\title{
Instantaneous Baseline Structural Damage Detection Using a Miniaturized Piezoelectric Guided Waves System
}

\author{
Seunghee Park*, Steven R. Anton**, Jeong-Ki Kim***, Daniel J. Inman****, and Dong S. Ha*****
}

Erratum to:

KSCE Journal of Civil Engineering (2010) 14(6):889-895

DOI $10.1007 / \mathrm{s} 12205-010-1137-\mathrm{x}$

The original version of this article unfortunately contained a mistake.

Erratum:

In "Acknowledgements", the project name, "u-City Master and Doctor Support Project", should be changed to "Cutting-edge Urban Development - Korean Land Spatialization Research Project (06KLSGC01)".

*Member, Assistant Professor, Dept. of Civil and Environmental Engineering, Sungkyunkwan University, Suwon 440-746, Korea (Corresponding Author, E-mail: shparkpc@skku.edu)

**Ph.D. Candidate, Center for Intelligent Material Systems and Structures, Dept. of Mechanical Engineering, Virginia Tech, Blacksburg, VA 24061, USA

***Ph.D. Candidate, Center for Embedded Systems for Critical Applications, Dept. of Electrical and Computer Engineering, Virginia Tech, Blacksburg, VA 24061, USA

****Professor, Center for Intelligent Material Systems and Structures, Dept. of Mechanical Engineering, Virginia Tech, Blacksburg, VA 24061, USA

******Professor, Center for Embedded Systems for Critical Applications, Dept. of Electrical and Computer Engineering, Virginia Tech, Blacksburg, VA 24061, USA 